\title{
Article
}

\section{The Oxoglutarate Binding Site and Regulatory Mechanism Are Conserved in Ammonium Transporter Inhibitors GlnKs from Methanococcales}

\author{
Marie-Caroline Müller (1) and Tristan Wagner*
}

check for

updates

Citation: Müller, M.-C.; Wagner, T. The Oxoglutarate Binding Site and

Regulatory Mechanism Are

Conserved in Ammonium

Transporter Inhibitors GlnKs from Methanococcales. Int. J. Mol. Sci. 2021,

22, 8631. https://doi.org/

$10.3390 /$ ijms 22168631

Academic Editor: Sung-Kun

(Sean) Kim

Received: 15 July 2021

Accepted: 5 August 2021

Published: 11 August 2021

Publisher's Note: MDPI stays neutral with regard to jurisdictional claims in published maps and institutional affiliations.

Copyright: (C) 2021 by the authors. Licensee MDPI, Basel, Switzerland. This article is an open access article distributed under the terms and conditions of the Creative Commons Attribution (CC BY) license (https:// creativecommons.org/licenses/by/ $4.0 /)$.
Microbial Metabolism Research Group, Max Planck Institute for Marine Microbiology, Celsiusstraße 1, 28359 Bremen, Germany; mmueller@mpi-bremen.de

* Correspondence: twagner@mpi-bremen.de

\begin{abstract}
Protein inhibition is a natural regulatory process to control cellular metabolic fluxes. $\mathrm{P}_{\mathrm{II}}{ }^{-}$ family signal-transducing effectors are in this matter key regulators of the nitrogen metabolism. Their interaction with their various targets is governed by the cellular nitrogen level and the energy charge. Structural studies on $\mathrm{GlnK}$, a $\mathrm{P}_{\mathrm{II}}$-family inhibitor of the ammonium transporters (Amt), showed that the T-loops responsible for channel obstruction are displaced upon the binding of 2-oxoglutarate, magnesium and ATP in a conserved cleft. However, GlnK from Methanocaldococcus jannaschii was shown to bind 2-oxoglutarate on the tip of its T-loop, causing a moderate disruption to GlnK-Amt interaction, raising the question if methanogenic archaea use a singular adaptive strategy. Here we show that membrane fractions of Methanothermococcus thermolithotrophicus released GlnKs only in the presence of Mg-ATP and 2-oxoglutarate. This observation led us to structurally characterize the two GlnK isoforms apo or in complex with ligands. Together, our results show that the 2-oxoglutarate binding interface is conserved in GlnKs from Methanococcales, including Methanocaldococcus jannaschii, emphasizing the importance of a free carboxy-terminal group to facilitate ligand binding and to provoke the shift of the T-loop positions.
\end{abstract}

Keywords: $\mathrm{P}_{\mathrm{II}}$-family protein; 2-oxoglutarate; nitrogen regulation; $\mathrm{X}$-ray crystal structure; conformational switch; energy charge; methanogenic archaea; marine thermophile

\section{Introduction}

$\mathrm{P}_{\mathrm{II}}$-family proteins are key players in the regulation of nitrogen metabolism in bacteria, archaea and in the plastids of plant/algae [1]. Their functions can include ammonium transport inhibition [2,3], ammonium-fixation regulation by indirectly or directly controlling the glutamine synthetase $[4,5]$ and $\mathrm{N}_{2}$-fixation inhibition by interfering with the dinitrogenase reductase [6,7]. $\mathrm{P}_{\text {II }}$ proteins are not limited by protein level regulation and can control gene transcription by interacting with transcriptional regulators involved in nitrogen assimilation [8,9]. Their known range of action was recently extended to the control of $\mathrm{CO}_{2}$-fixation and sensing of fluctuating inorganic carbon levels in cyanobacteria $[10,11]$ and it is expected that such fascinating sensors might also have undescribed roles in nature. Most of $\mathrm{P}_{\mathrm{II}}$ proteins are regulated by the binding of two effectors: 2-oxoglutarate (2OG), whose concentration depends on the cellular carbon and nitrogen status (Figure S1), and ADP/ATP, which are indicators of the energy charge [12,13]. Because of their regulatory importance, numerous $\mathrm{P}_{\mathrm{II}}$ protein structures from different organisms were elucidated. All $P_{\text {II }}$ proteins known so far show a typical homotrimeric organization [14]. The monomeric unit, of circa $11-18 \mathrm{kDa}$, consists of two $\alpha$-helices, four $\beta$-strands (organized in a double ferredoxin-like fold $\beta 1 \alpha 1 \beta 2 \beta 3 \alpha 2 \beta 4$ ) and three protruding loops called B, C and T [14]. In the trimeric state, clefts are formed at the dimeric interface through the interaction of the B-loop and the base of the T-loop of one subunit with the C-loop of the adjacent one. These clefts constitute the binding site for ADP/ATP, magnesium (Mg) and 2OG $[1,7,14,15]$. The 
T-loop is of greater importance since it has been determined to be essential for the interaction with target proteins. Furthermore, it contains the residue Tyr51, a site of uridylylation in bacteria, which strongly affects target binding $[1,16]$.

Detailed studies highlighted the molecular mode of interaction between the $\mathrm{P}_{\mathrm{II}^{-}}$ family protein GlnK and its target, the ammonium channel Amt. First described in Escherichia coli [2,3], crystal structures of GlnK-Amt revealed the intimacy of the interaction. GlnK in complex with ADP binds Amt in a 3:3 ratio where each ordered T-loop is inserted into one of the cytoplasmic exit channels of the Amt trimer. Ammonia transfer through the channel is physically blocked by the GlnK sidechain Arg41 located on the T-loop. While ADP promotes GlnK-Amt complexation, the opposite is the case for the binding of the effectors ATP, Mg and 2OG, which lead to a shift in the T-loop positions further outward from the center of the trimer, precluding an insertion into the Amt exit channels [17]. ATP and $\mathrm{Mg}$ are required for 2OG binding. 2OG triggers the conformational rearrangement of the T-loop.

Studies in archaea revealed a well-conserved mode of action and regulation of GlnK homologues $[17,18]$. However, structural and biochemical investigations by Yildiz et al. on the GlnK-Amt system in the hyperthermophile Methanocaldococcus jannaschii suggested that methanogenic archaea have a different type of regulation [19]. They obtained a crystal structure of $\mathrm{GlnK}_{1}\left(\mathrm{MjGlnK}_{1}\right)$ in which the 2OG was found to be bound at the top of the T-loop instead of the inter-subunit cleft (Figure S2) [19]. In this scenario, the 2OG attached at the top of the T-loop would prevent GlnK association to Amt and therefore allow ammonium import. Yet, recombinantly expressed $M j \mathrm{Amt}_{1}$ and $M j G \ln \mathrm{K}_{1}$ showed an almost complete dissociation when only ATP and Mg were added while 2OG addition by itself showed moderate dissociation. Since Methanococcales are energy extremophiles with a majority of diazotrophs among them [20], a tuning of the GlnK regulation with a reduced effect of $2 \mathrm{OG}$ might have occurred to allow a stronger influence of the cellular energy charge compared to the carbon and nitrogen status.

To verify this hypothesis, we studied the behavior of GlnK-Amt in membrane extracts from Methanothermococcus thermolithotrophicus (a thermophilic marine methanogen) and performed structural analyses on all present GlnK isoforms $\left(M t G \operatorname{lnK} K_{1}\right.$ and $\left.M t G \operatorname{lnK} K_{2}\right)$ as well as $\mathrm{GlnK}_{1}$ from Methanocaldococcus jannaschii without a C-terminal tag $\left(M j \mathrm{GlnK}_{1}{ }^{\mathrm{woT}}\right)$. By combining biochemistry studies with structural analyses, we showed that GlnKs from Methanococcales bind 2OG in the same binding site as and with the same mechanism of typical proteins in the $\mathrm{P}_{\mathrm{II}}$-family.

\section{Results}

\subsection{OG, Mg and ATP Are Required to Disrupt MtGlnKs from the Membrane Fraction}

Two isoforms of Amt and their respective GlnK regulator are present in the genome of $M$. thermolithotrophicus (Figure S3). They co-localize in the same part of the genome, in contrast to the dispatched organization in M. jannaschii. The role of ATP, Mg and 2OG as the physiological triggers to release GlnK from Amt was investigated by using membrane fractions natively isolated from $M$. thermolithotrophicus. During cell lysis, the concentration of the cellular ATP, Mg and 2OG was considered to be sufficiently low to allow the binding of GlnKs to Amt. The membrane resuspension was then washed several times and incubated with different combinations of ATP, ADP, GTP, Mg and 2OG to observe the influence on GlnK release. An ultracentrifugation step was used after incubation to separate unbound proteins, these supernatants were concentrated and passed on SDS PAGE. As shown in Figure 1, a band migrating at circa $12-\mathrm{kDa}$ appeared when ATP, $\mathrm{Mg}$ and 2OG were added together. The band was identified by mass spectrometry and mainly contains $M t G \ln K_{1}$ and $M t G \ln K_{2}$. The peptide counts indicate $M t G \ln K_{2}$ as the predominant isoform under this condition with a ratio of one $M t G \operatorname{lnK} K_{1}$ for two $M t G l n K_{2}$ (see Section 4.3). When only ATP and 2OG were added without $\mathrm{Mg}$, a moderate release of GlnKs was observed that could be explained by residual cations bound to the membrane preparation. ADP or GTP did not disrupt the interaction and a ratio of 1:10 or 1:1 ADP/ATP had no influence on the released amount 
of $M t G \operatorname{lnKs}$ (Figure 1). The observed release of GlnKs from the membrane fraction upon addition of Mg-ATP/2OG fit the established model for GlnK ligand interaction [17,21]. However, they differ from the results obtained with the recombinant $\mathrm{Amt}_{1}$ and $\mathrm{GlnK}_{1}$ from M. jannaschii expressed in E. coli, in which the addition of Mg-ATP alone resulted in $95 \%$ of $\mathrm{Amt}_{1} / \mathrm{GlnK}_{1}$ dissociation and 2OG alone resulted in 30\% of complex disruption [19].

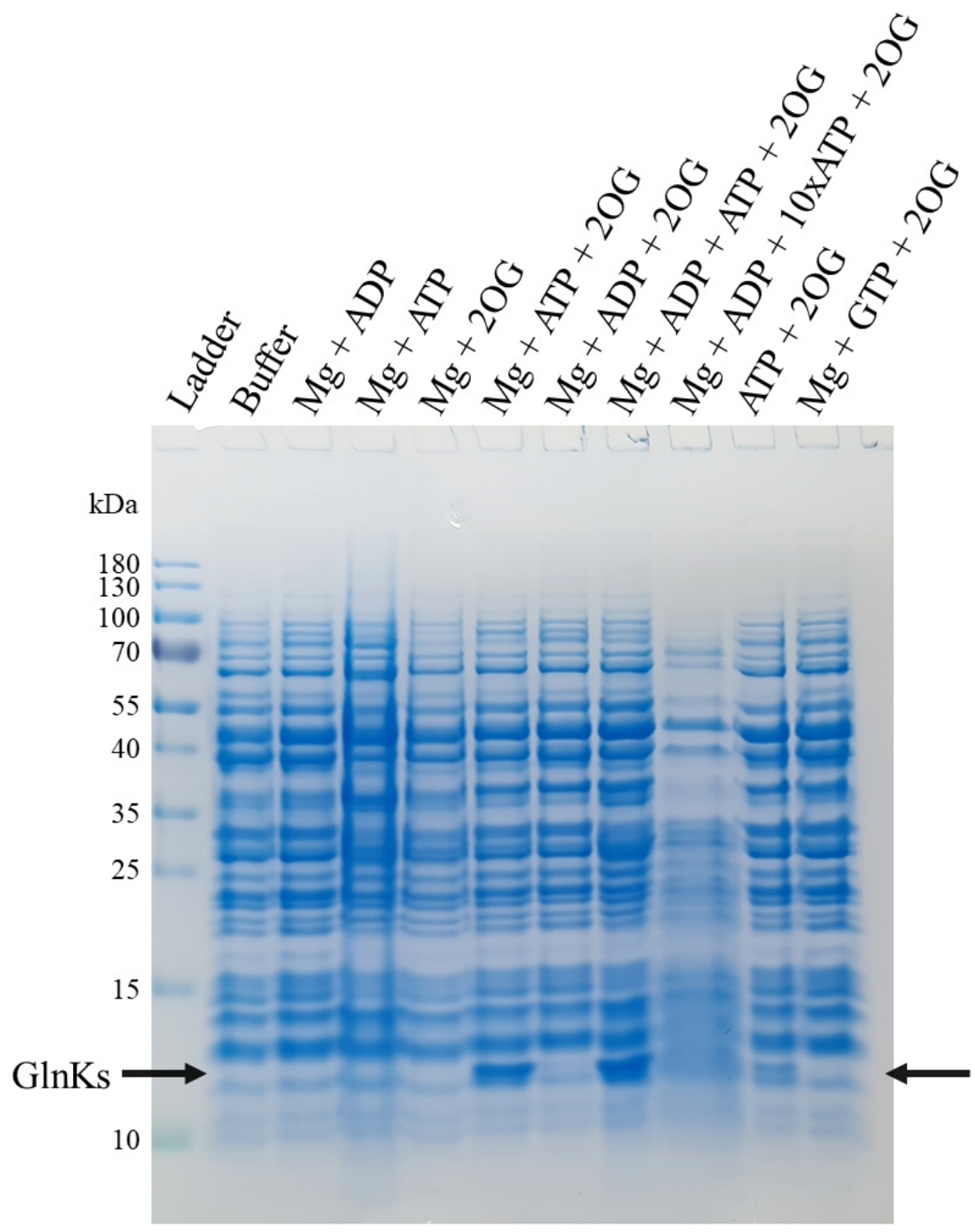

Figure 1. SDS-PAGE of the membrane release experiment with different added ligands. Arrows indicate the position of $M t G \operatorname{lnKs}$ on the gel.

Such discrepancies between $M$. jannaschii and other studied systems led us to examine the structure of $M j \mathrm{GlnK} \mathrm{K}_{1}$. Compared to the structures of other GlnKs in complex with Mg-ATP and 2OG, the C-terminal His-tag of $M j \mathrm{GlnK}_{1}$ seems to interfere with the 2OG binding site (Figure S2) as already laid out by Truan and collaborators [22]. To evaluate the C-terminal extension's effect on ligand binding, $M j G \ln K_{1}$ was produced and crystallized without a tag. Additionally, we performed structural studies on both $M t G \operatorname{lnK}$ s isoforms to learn if Methanococcales share a conserved ligand-binding site and conformational switch.

\section{2. $M t G \ln K_{1}$ and $M t G \ln K_{2}$ Show Remarkable Purification and Crystallization Behaviors}

On the way to the crystal structures, we observed astonishing biochemical and crystallization properties of both GlnKs from M. thermolithotrophicus. Both N-terminal tagged isoforms were highly expressed and soluble; however, they could not bind on Nickel-NTA 
resin, probably because of tag hindrance. Since this protein family has been shown to remarkably tolerate high temperatures and to spontaneously refold [23], a boiling step was performed on the soluble cell extract. $M t G \operatorname{lnKs}$ tolerated more than $60 \mathrm{~min}$ at $70^{\circ} \mathrm{C}$ without showing signs of deterioration (Figure S4A). Therefore, this step was used to facilitate their purification. Surprisingly, both isoforms aggregated when placed at $4{ }^{\circ} \mathrm{C}$ in a buffer devoid of salts (50 mM Tricine pH 8, 2 mM DTT, Figure S4B). The white flocks were separated from E. coli contaminants by centrifugation and the pellet contained a remarkably pure protein preparation (Figure $\mathrm{S} 4 \mathrm{C}$ ), which could be solubilized by increasing the salinity (e.g., $500 \mathrm{mM} \mathrm{NaCl}$ ) and the temperature (e.g., $25-70^{\circ} \mathrm{C}$ ). This treatment maintained the protein solubility and no aggregates were observed during gel filtration (see Section 4.4).

The boiling step was also used to purify $M j \mathrm{GlnK}_{1}{ }^{\text {woT }}$ and the preparation was considerably enriched using this method; however, compared to $M t G \operatorname{lnKs}$, the protein did not precipitate at $4{ }^{\circ} \mathrm{C}$ after an overnight incubation and a gel filtration step was performed to further purify the protein (see Section 4.4). $M t G \ln K_{1}$ without ligands and $M t G \ln K_{2}$ with Mg-ATP/2OG formed macroscale-size crystals in seconds (see Section 4.5). Growth kinetics could be very well controlled by modifying the protein concentration (Figure S4D). Crystals growth could also be controlled via temperature, for instance, it was possible to obtain large usable macro-crystals from micro-crystals by repeating an incubation of the crystallization tray at $46^{\circ} \mathrm{C}$ for $3 \mathrm{~min}$ followed by incubation at $18^{\circ} \mathrm{C}$ (Figure S4E). $M t \mathrm{GlnK}_{1}$ and $M t \mathrm{GlnK} \mathrm{K}_{2}$, crystallized without ligands formed crystals belonging to trigonal and orthorhombic forms that diffracted to a resolution of 1.94 and $2.30 \AA$, respectively. The $M t \mathrm{GlnK}_{2}$ and $M j \mathrm{GlnK}_{1}{ }^{\text {woT }}$ crystals with Mg-ATP/2OG belonging to tetragonal and rhombohedral forms diffracted to an almost atomic resolution of $1.16 \AA$ and $1.20 \AA$, respectively. This resolution allowed us to reach a high level of detail for the structural analyses.

This one-day two-step purification protocol without the need for column chromatography providing fast crystallization of high-quality diffracting crystals highlights $M t G \operatorname{lnKs}$ as accessible protein benchmarks for crystallization and crystallography studies.

\subsection{Conformational Rearrangement upon Ligand Binding}

All obtained structures exhibit the typical trimeric organization and typical fold of the $\mathrm{P}_{\mathrm{II}}$-family in which $\beta$-sheets organize the trigonal core while the $\alpha$-helices are located at the periphery (Figures 2A and S5), as described in other work [14,24]. The three main loops, T(residues 36-55), B- (residues 82-89) and C- (residues 102-112) were identified based on their high structural similitude with the GlnK homologue from A. fulgidus (Figure 2A). The $\mathrm{N}$-terminal His-tag is only partially observable in the $M t \mathrm{GlnK}_{2}-\mathrm{Mg}$-ATP/2OG structure and appears to be highly flexible, without interfering with the ligand binding site.

Unexpectedly, the structure of $M t G \ln K_{1}$ crystallized without ligands contains an additional electron density in the cleft surrounded by the three loops. A 2'-deoxyadenosinediphosphate (dADP) molecule was modelled with high confidence (Figures 3A and S6). Since no nucleotide was added during the purification, the metabolite must originate from the E. coli cytoplasm and has been retained during the whole purification. dADP is coordinated by a network of hydrogen bonds from Thr29', Ile38, Gln39, Gly87, Asp88, Lys90, Ala64', Arg101' and Arg103'. This state has a similar nucleotide coordination and T-loop positions compared to the E. coli AmtB-GlnK structure (Figure S7). We suggest that the presence of a dADP rather than ADP is artefactual and we consider that dADP would not influence the T-loop coordination differently compared to ADP (Figure 3D). 
A
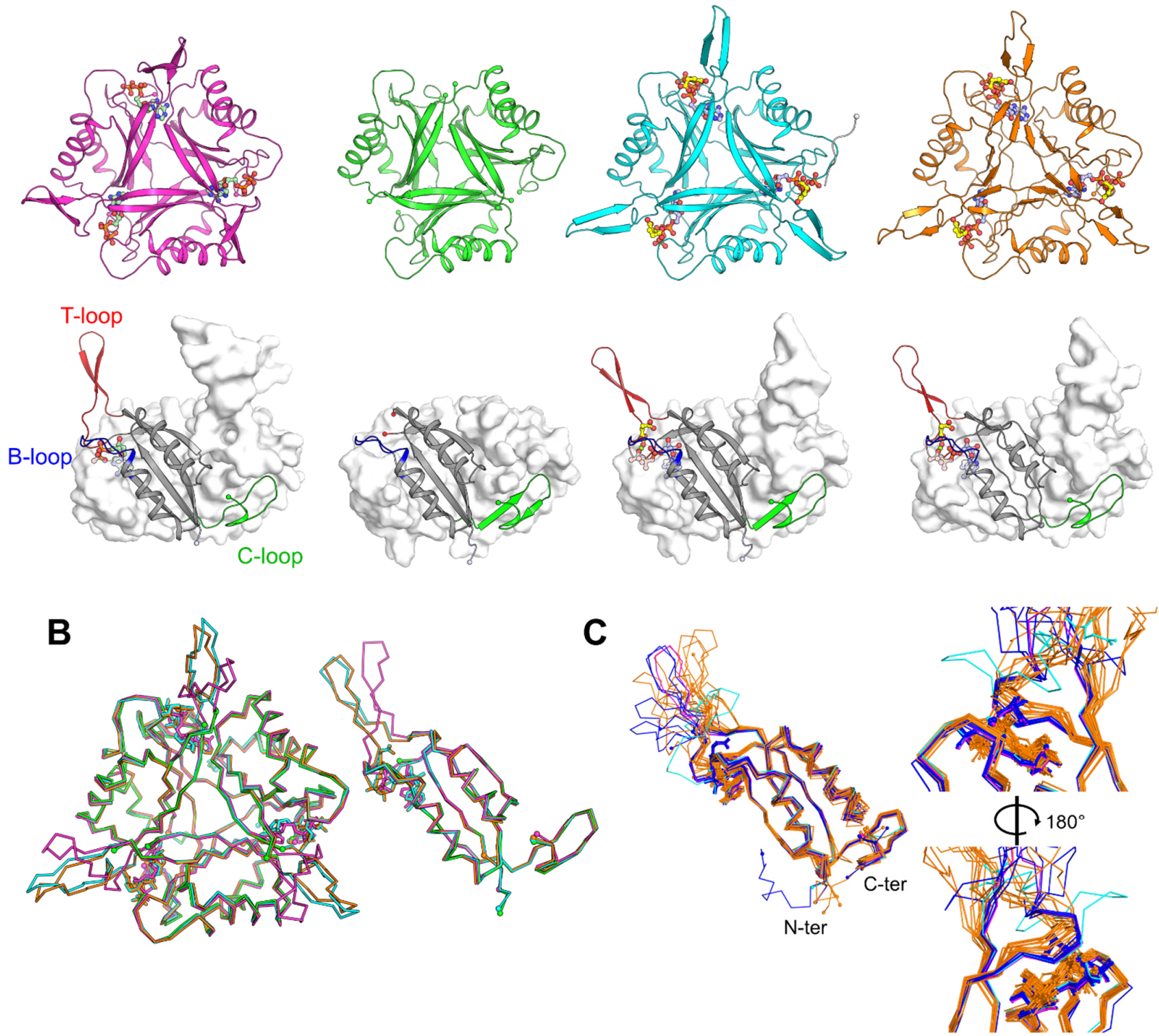

Figure 2. Crystal structures and comparison of the different states of GlnKs from Methanococcales. (A) Top row: Trimeric GlnK structures are represented in cartoon with ligands in ball and stick. Bottom row: one chain is in cartoon representation while the two others are displayed as white surface. The T-, B- and C-loops are colored in red, blue and green, respectively. Carbon atoms are colored in yellow for 2OG, in pale green for dADP, in pale blue for ATP while nitrogen, oxygen, phosphorus and $\mathrm{Mg}$ are colored in blue, red, orange and green, respectively. The N-terminal tag of $M t G \ln K_{2}-\mathrm{Mg}-\mathrm{ATP} / 2 \mathrm{OG}$ is colored in light grey and belongs to the symmetry mate. $\mathrm{N}$ - and C-termini as well as the cut in the T-loop are shown with spheres. (B) Superposition of all obtained structures as trimer (left) and monomer (right) in ribbon and stick representation. Chains and atoms are colored according to panel A top. (C) Superposition of all available $\mathrm{P}_{\text {II }}$ structures containing ADP or $\mathrm{Mg}-\mathrm{ATP} / 2 \mathrm{OG}$ are shown in ribbon with ligands in sticks (see Figure S5 for more details). Structures with ADP are colored

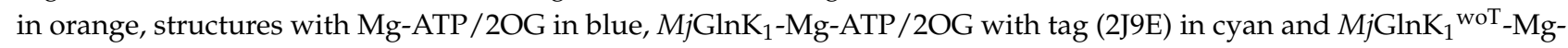
ATP/2OG in pink. Overall view of the monomer (left panel) and close-up of the ligand binding site (right).

An extra electron density for nucleotides does not exist in the ligand-binding site of the $M t G \ln K_{2}$ apo structure and seems to be replaced by water molecules. However, an additional electron density lies between the modelled $\mathrm{GlnK}_{2}$ trimers composing the asymmetric unit. The resolution limit, the high twinned fraction (0.39) as well as high translational non-crystallography symmetry $(56 \%)$ and the poorly defined extra electron density restrained us from placing a model that seems to be an $M t \mathrm{GlnK}_{2}$ homodimer. 
A

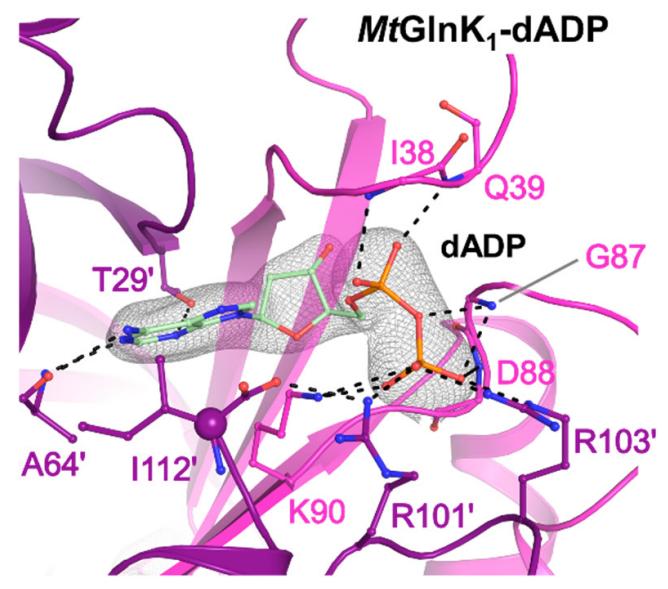

B

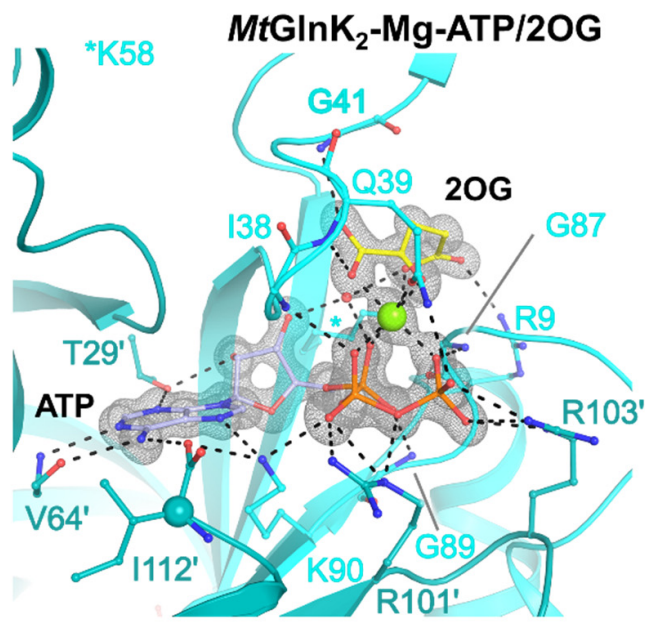

C

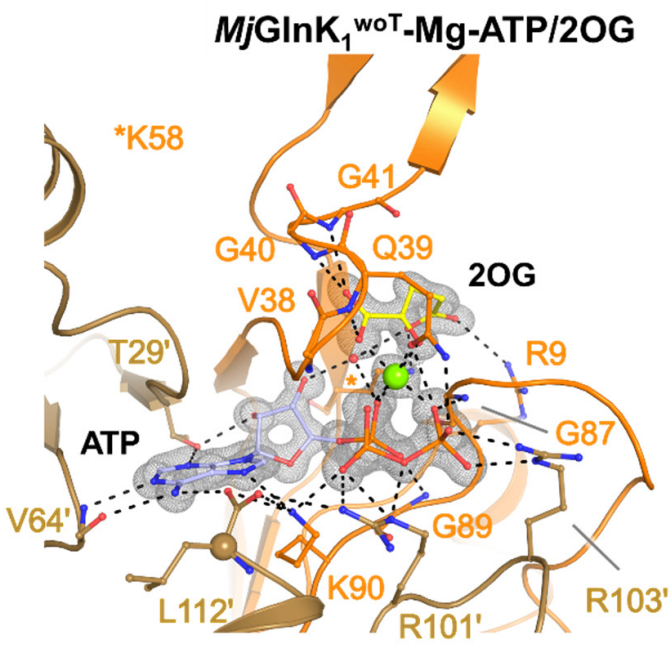

D

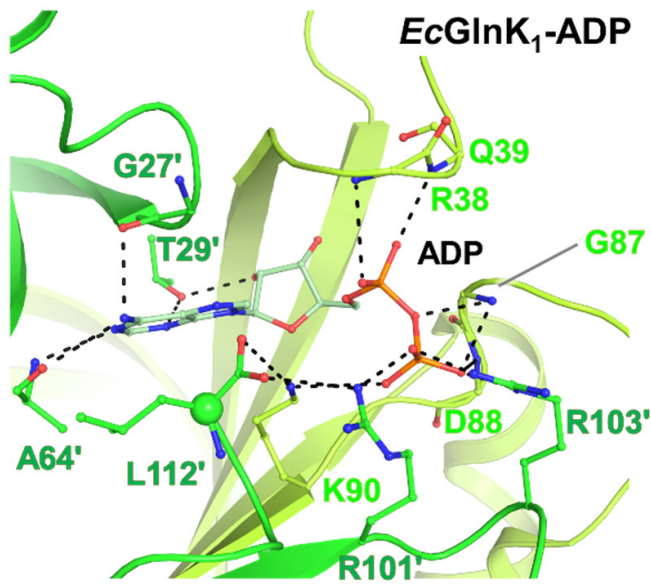

E

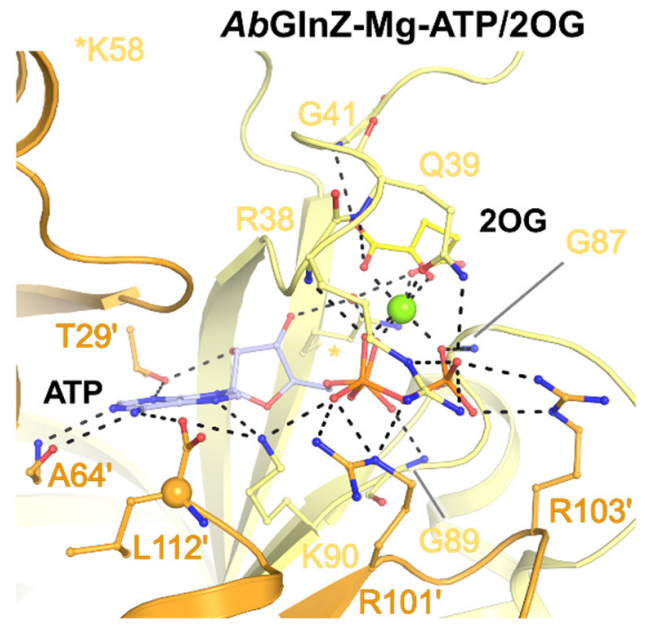

F

MjGInK ${ }_{1}$-Mg-ATP/2OG

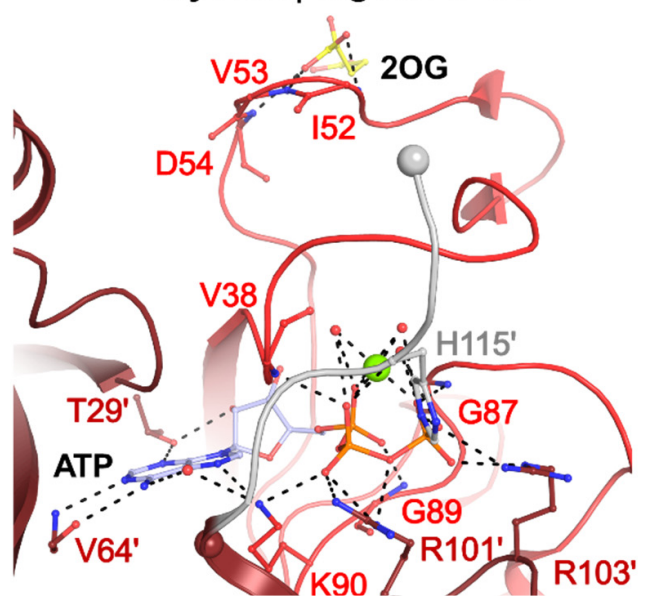

Figure 3. Ligand binding sites. For all panels, the main chain is represented in cartoon. Ligands, main and side chains of the residues participating in ligand binding are shown as ball and stick. Carbon atoms are colored in yellow for 2OG, in pale green for AADP and ADP, in pale blue for ATP while nitrogen, oxygen, phosphorus and Mg are colored in blue, red, orange and green, respectively. C-termini are highlighted by a sphere. Electron density maps $\left(2 F_{\mathrm{O}}-F_{\mathrm{C}}\right)$ around the ligands are contoured at $2-\sigma$ and shown as grey mesh. Polar contacts are indicated by black dashes. (A) $M t G l n K_{1}-$ dADP, (B) $M t G \ln K_{2}-\mathrm{Mg}-\mathrm{ATP} / 2 \mathrm{OG},(\mathrm{C}) \mathrm{MjGlnK}{ }_{1}{ }^{\text {woT }}$-Mg-ATP/2OG, (D) E. coli GlnK-ADP (PDB:2NUU), (E) Azospirillum brasilense GlnZ-Mg-ATP/2OG (PDB:3MHY), (F) tagged MjGlnK 1 -Mg-ATP/2OG (PDB:2J9E) with its C-terminal tag colored in light grey. 


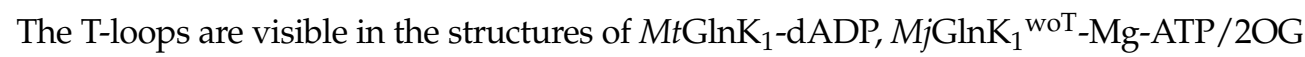
and $M t G \ln K_{2}-\mathrm{Mg}$-ATP/2OG. Modelled T-loops are, however, still more flexible compared to the core of the protein due to their high local B-factors. The T-loop's tip positions might be influenced due to their participation in the crystal packing (Figure S8). As expected, the T-loop is drastically switching position between the $M t G \ln K_{1}$-dADP and the ternary complex structure from $M t G \ln K_{2}-\mathrm{Mg}-\mathrm{ATP} / 2 \mathrm{OG}$ and $M j \mathrm{GlnK}_{1}{ }^{\text {woT }}$-Mg-ATP/2OG (Figure 2B), with a maximum deviation of $11.3 \AA$ and $10.7 \AA$, respectively (measured at the $\mathrm{C} \alpha$ of the $\operatorname{Arg} 47$ ).

Structure comparison of the ternary complexes from $M t \mathrm{GlnK}_{2}-\mathrm{Mg}$-ATP/2OG and $\mathrm{MjGlnK}{ }_{1}{ }^{\mathrm{woT}}$-Mg-ATP/2OG and structural homologues shows an excellent fit of the T-loop at its base (Figures 2C and S5) and some deviation at the top of the loop which could be due to the crystal contacts. In comparison, the structure of tagged $M j \mathrm{Gln} \mathrm{K}_{1}$ with $\mathrm{Mg}$-ATP and 2OG shows a striking deviation. This difference likely results from an effect of the tag (Figure S2). Therefore, a close inspection of the ligand-binding site was warranted.

\subsection{The Free Carboxy-Terminal Is Indirectly Stabilizing 2OG Binding}

$M t \mathrm{GlnK}_{2}$ and $M j \mathrm{Gln} \mathrm{K}_{1}{ }^{\mathrm{woT}}$ structures, co-crystallized with Mg-ATP and 2OG, offered a very clear picture of the ligand coordination due to their very high-resolution (see Section 4.6). Both structures show an almost identical coordination of the ligands. The adenine part of ATP is flanked by the phenyl group of Phe92 and the whole molecule is coordinated by hydrogen bonds from Thr29', Ile38, Gln39, Gly87, Lys90, Val64' , Arg101' and Arg103' (residues are based on $M t \mathrm{GlnK}_{2}$, Figure 3B,C). For the 2OG, the keto group is coordinated by the backbone of Gln39, Gly41, while the Arg9 and Lys58 coordinate the carboxy group via salt bridges. The carboxy group has an equivalent position as the Gln39 side chain in the $M t \mathrm{GlnK}_{1}$-dADP structure. Mg plays an important role as a bridging agent, binding the three phosphate groups of the ATP, the keto acid group of the 2OG and the side chain of Gln39 that closes the hexa-coordination (Figure 3B,C). The residues involved in ligandbinding are conserved to a certain extent throughout the $\mathrm{P}_{\mathrm{II}}$-family (Figure 4). The residues binding ligands by their main chain can be variable and the ones binding through the side chains are all well conserved.

A superposition of each three different chains of the tagged and untagged $M j \mathrm{GlnK}_{1}$ with Mg-ATP and 2OG shows a different position of the C-loop and the effect of the tag (Figure S9). In $M j \mathrm{GlnK}_{1}{ }^{\mathrm{woT}}$, the carboxy-terminus is coordinating the adenine ring and the Lys90, the latter adequately engages a salt bridge with the $\beta$-phosphate of the ATP. The carboxy-terminus is itself locked by the side chain of the Ile via hydrophobic interaction. Such a critical position seems to be very well conserved in GlnK-subfamily as observed in A. brasilense GlnZ [22] (Figure 3E). Therefore, we propose that the absence of the carboxy-terminal provokes a slight displacement of the Lys90 that shifts the coordination of the $\beta$-phosphate group. Moreover, the addition of the poly-histidine tag displaces the $\mathrm{Mg}$ which cannot bind the 2OG anymore (Figure 3F). The absence of an appropriate $2 \mathrm{OG}$ coordination blocks the correct positioning of the T-loops and led to its aberrant conformation (Figure S9). 

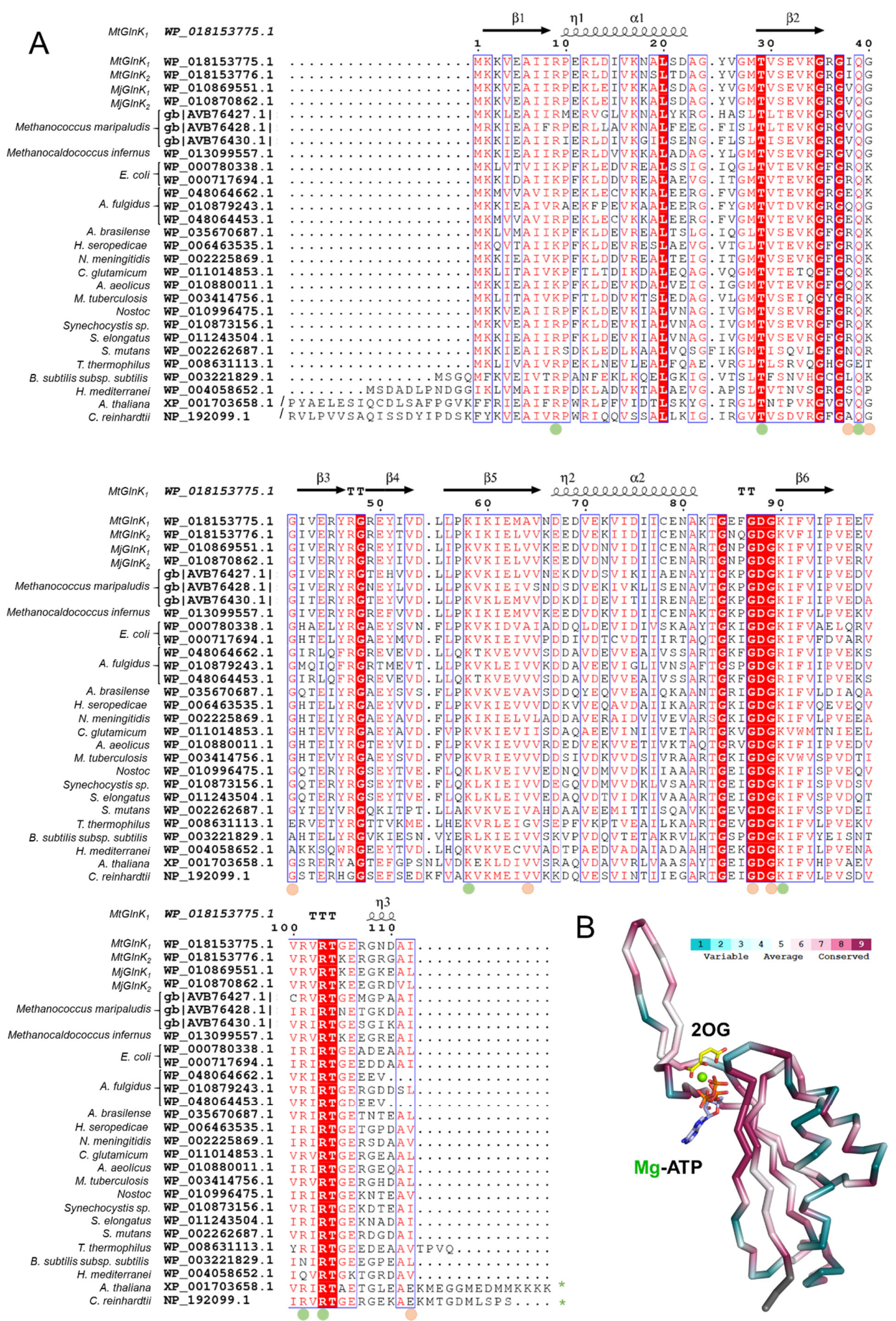

Figure 4. Sequence conservation among structurally characterized $P_{I I}$ members with the addition of various Methanococcales (see Supplemental materials for the full names). (A) Sequences were aligned with Clustal omega and processed with Espript 3.0. $M t G \ln K_{1}$ was used as a reference for the secondary structure. Dots indicate residues involved in ligand binding via side chain (green) or main chain (orange). Green stars indicate a C-terminal extension (Q-loop). (B) Sequence conservation score superposed on the 3D-structure of $M t G \ln K_{2}-\mathrm{Mg}$-ATP/2OG monomer processed via the ConSurf Server [25,26]. The conservation is represented as a color gradient, from blue (variable) to dark red (conserved). Nitrogen, oxygen, phosphorus and $\mathrm{Mg}$ are colored in blue, red, orange and green, respectively. Carbons of 2OG and ATP are colored yellow and pale blue, respectively. 


\section{Discussion}

$\mathrm{P}_{\mathrm{II}}$-family proteins represent a large class of regulators found across the three domains of life [27] and are involved in maintaining the cellular carbon/nitrogen balance. They share a high structural conservation and ligand binding mode that pose them as an ideal target for drug design with a focus on nitrogen regulation. New exciting discoveries pointed out that $\mathrm{P}_{\mathrm{II}}$-family proteins are not restrained to the cellular nitrogen control but also carbon-fluxes in cyanobacteria $[10,11]$. Therefore, with expanding availability of $P_{I I}$ protein sequences, biochemical characterizations are needed to elucidate yet undiscovered physiological functions, targets and regulation systems. The T-loop is the essential component for target interaction and can vary in length and composition depending on the system. It contains key residues targeted for post-translational modification in some organisms and undergoes conformational changes upon ADP/ATP-Mg-2OG binding. While 2OG reflects the cellular nitrogen/carbon status, the ADP/ATP balance represents the energy level of the cell, an important factor for methanogenic archaea, considered to be energy extremophiles. Therefore, it could be possible that nitrogen regulation in these microorganisms may be regulated exclusively by the ADP/ATP balance instead of the cellular 2OG concentration. This hypothesis appears to be supported by previous work on $M$. jannaschii where 2OG was found to have a reduced effect on the $\mathrm{Amt}_{1} / \mathrm{GlnK}_{1}$ disruption caused by a different $2 \mathrm{OG}$ binding mode. Such exception among $\mathrm{P}_{\mathrm{II}}$-family proteins is not unique, as $\mathrm{GlnK}_{2}$ from $A$. fulgidus and SbtB from cyanobacteria were not found to bind 2OG [11,28].

The results described here point out that the unconventional behavior observed in $M$. jannaschii is most likely due to the C-terminal His-tag of the $M j \mathrm{GlnK}_{1}$ construct. The tag hides the terminal carboxy group and indirectly displaces the loop coordinating the 2OG, generating an altered position of the T-loop. As proposed before by Truan and coworkers [22], the carboxy-terminal group is of importance for ligand binding stabilization. The tag in the $\mathrm{N}$-terminal position seems less consequential, as we did not see any differences in ligand

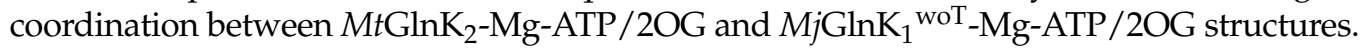

Interestingly, a free $\mathrm{C}$-terminal carboxy group at an equivalent position is not critical for ligand binding as shown in other $\mathrm{P}_{\mathrm{II}}$-family proteins that contain a C-terminal extension. For instance, in Chlamydomonas reinhardtii and Arabidopsis thaliana the C-terminus is extended by the so-called Q-loop able to bind glutamine [29]. In the structure of the $\mathrm{P}_{\mathrm{II}}$-family protein from C. reinhardtii containing Mg-ATP and 2OG, the end of the C-loop and the whole Q-loops are flexible and not modelled. Compared to GlnK, this protein harbors an $\mathrm{N}$-terminal extension folded close to the $\mathrm{C}$-loop that might be an adaptation to the loss of the free carboxy group in the C-terminus.

Our studies also highlighted that $M t G \ln K_{1}$ is able to bind a deoxynucleotide without provoking further structural changes (Figures 3A, S6 and S7). The dADP might come from an artefact during the boiling procedure and its physiological relevance should be investigated in the future. Intriguingly, it seems that $M t G l n K s$ switch is not under the dependency of the energy charge since addition of ADP to the membrane experiment did not inhibit the release. However, we cannot exclude a possible effect of AMP to displace the equilibrium toward an activation of GlnKs.

Both $M t \mathrm{G} \operatorname{lnK}$ isoforms were detected in the membrane dissociation experiment and one can wonder why this organism would have two versions of Amt and GlnK especially if these isoforms vary barely in sequence and structure. Solid-supported membrane electrophysiology on Amts from A. fulgidus proved that even with low divergence sequences, functional differences exist between the three different isoforms [30]. The associated GlnK regulators might be tuned up to also recognize their specific transporters. Therefore, we tentatively modelled $M t A_{1} t_{1}$ (WP_018153774) and $M t A m t B_{2}$ (WP_018153777) based on an E. coli structure (PDB: 2NUU) to visualize the surface charges of the binding interface between $M t G \operatorname{lnKs}$ and their transporters (Figure S10). Since electrostatic charges are very similar for both $M t G \operatorname{lnKs}$ we cannot conclude on the specificity towards the two modelled AmtB isoforms. However, our model supports that in the dADP-bound state, the T-loop could in theory block the $\mathrm{NH}_{3}$-channel after slight repositioning as shown in E. coli 
structures. Contrarily, the fixed T-loop positions in the Mg-ATP/2OG bound state prevent insertion into the Amt channel, as demonstrated in previous studies [17].

\section{Materials and Methods}

\subsection{Cultivation of M. thermolithotrophicus}

M. thermolithotrophicus strain DSM 2095 was ordered from the Deutsche Sammlung von Mikroorganismen und Zellkulturen (DSMZ, Leibniz, Germany) and was cultivated at $65^{\circ} \mathrm{C}$ in a minimal mineral medium. For one liter of medium the compounds listed in Table 1 were subsequently dissolved in $750 \mathrm{~mL}$ of deionized $\mathrm{H}_{2} \mathrm{O}\left(\mathrm{dH}_{2} \mathrm{O}\right)$. The $\mathrm{pH}$ was set to 6 with $\mathrm{NaOH}$ pellets. The media was filled up to a final volume of $1 \mathrm{~L}$ by the addition of $\mathrm{dH}_{2} \mathrm{O}$.

Table 1. Medium components for M. thermolithotrophicus cultivation.

\begin{tabular}{|c|c|c|}
\hline Compound & Amount & Final Molarity \\
\hline $\mathrm{K}_{2} \mathrm{HPO}_{4}$ & $55.7 \mathrm{mg}$ & $0.32 \mathrm{mM}$ \\
\hline $\mathrm{KH}_{2} \mathrm{PO}_{4}$ & $55.8 \mathrm{mg}$ & $0.41 \mathrm{mM}$ \\
\hline $\mathrm{KCl}$ & $1 \mathrm{~g}$ & $13.4 \mathrm{mM}$ \\
\hline $\mathrm{NaCl}$ & $25.13 \mathrm{~g}$ & $430 \mathrm{mM}$ \\
\hline $\mathrm{NaHCO}_{3}$ & $0.81 \mathrm{~g}$ & $10 \mathrm{mM}$ \\
\hline $\mathrm{CaCl}_{2} \cdot 2 \mathrm{H}_{2} \mathrm{O}$ & $367.5 \mathrm{mg}$ & $2.5 \mathrm{mM}$ \\
\hline $\mathrm{MgCl}_{2} \cdot 6 \mathrm{H}_{2} \mathrm{O}$ & $7.725 \mathrm{~g}$ & $38 \mathrm{mM}$ \\
\hline $\mathrm{NH}_{4} \mathrm{Cl}$ & $1.18 \mathrm{~g}$ & $22.06 \mathrm{mM}$ \\
\hline $\mathrm{Fe}\left(\mathrm{NH}_{4}\right)_{2}\left(\mathrm{SO}_{4}\right)_{2} \cdot 12 \mathrm{H}_{2} \mathrm{O}$ & $29.92 \mathrm{mg}$ & $0.031 \mathrm{mM}$ \\
\hline Nitrilotriacetic acid & $61.16 \mathrm{mg}$ & $0.32 \mathrm{mM}$ \\
\hline $2 \mathrm{mM} \mathrm{Na}_{2} \mathrm{SeO}_{3} \cdot 5 \mathrm{H}_{2} \mathrm{O}$ stock & $10 \mu \mathrm{L}$ & $0.02 \mu \mathrm{M}$ \\
\hline $\mathrm{Na}_{2} \mathrm{WO}_{4} \cdot 2 \mathrm{H}_{2} \mathrm{O}$ & $3.3 \mathrm{mg}$ & $0.01 \mathrm{mM}$ \\
\hline $\mathrm{Na}_{2} \mathrm{MoO}_{4} \cdot 2 \mathrm{H}_{2} \mathrm{O}$ & $2.42 \mathrm{mg}$ & $0.01 \mathrm{mM}$ \\
\hline MES & $9.76 \mathrm{~g}$ & $50 \mathrm{mM}$ \\
\hline $\mathrm{Na}_{2} \mathrm{SO}_{4}$ & $1.42 \mathrm{~g}$ & $10 \mathrm{mM}$ \\
\hline $1.5 \mathrm{mM}$ resazurin & $1 \mathrm{~mL}$ & $0.0015 \mathrm{mM}$ \\
\hline Trace element solution & $10 \mathrm{~mL}$ & \\
\hline
\end{tabular}

Trace element composition: A 100-fold-concentrated trace element solution was pre-

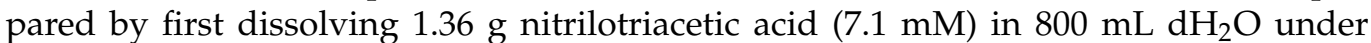
magnetic stirring. The $\mathrm{pH}$ was adjusted to 6.2 by adding $\mathrm{NaOH}$ pellets. The components listed in Table 2 were successively added and the solution was filled up to a final volume of $1 \mathrm{~L}$ with $\mathrm{dH}_{2} \mathrm{O}$.

M. thermolithotrophicus was grown under strict anaerobic condition in a $10 \mathrm{~L}$ fermenter containing $7 \mathrm{~L}$ of medium gassed with up to $50 \mathrm{kPa} \mathrm{H} / \mathrm{CO}_{2}$ and $50 \mathrm{kPa} \mathrm{N} \mathrm{N}_{2}$ under $500 \mathrm{rpm}$ stirring at $65{ }^{\circ} \mathrm{C}$. The fermenter was inoculated with $600 \mathrm{~mL}$ preculture cultivated in the same medium. The cells were grown until late exponential phase $\left(\mathrm{OD}_{600}\right.$ of 1.35$)$ and then immediately transferred in an anaerobic tent $\left(\mathrm{N}_{2} / \mathrm{CO}_{2}\right.$ atmosphere at a ratio of $\left.90: 10\right)$. Cells were harvested by anaerobic centrifugation for $30 \mathrm{~min}$ at $4500 \times \mathrm{g}$ at $18{ }^{\circ} \mathrm{C} .7 \mathrm{~L}$ of culture yielded $19.5 \mathrm{~g}$ of cells (wet weight). The cell pellet was transferred in a sealed bottle, gassed with $30 \mathrm{kPa}$ with $\mathrm{N}_{2}$, flash frozen in liquid $\mathrm{N}_{2}$ and stored at $-80^{\circ} \mathrm{C}$. 
Table 2. Trace element solution.

\begin{tabular}{ccc}
\hline Compound & Amount & Final Molarity \\
\hline $\mathrm{MnCl}_{2} \cdot 6 \mathrm{H}_{2} \mathrm{O}$ & $91.4 \mathrm{mg}$ & $0.45 \mathrm{mM}$ \\
\hline $\mathrm{FeCl}_{3} \cdot 6 \mathrm{H}_{2} \mathrm{O}$ & $183.3 \mathrm{mg}$ & $0.68 \mathrm{mM}$ \\
\hline $\mathrm{CaCl}_{2} \cdot 2 \mathrm{H}_{2} \mathrm{O}$ & $60.26 \mathrm{mg}$ & $0.76 \mathrm{mM}$ \\
\hline $\mathrm{CoCl}_{2} \cdot 6 \mathrm{H}_{2} \mathrm{O}$ & $180.8 \mathrm{mg}$ & $0.76 \mathrm{mM}$ \\
\hline $\mathrm{ZnCl}_{2}$ & $90 \mathrm{mg}$ & $0.66 \mathrm{mM}$ \\
\hline $\mathrm{CuSO}_{4} \cdot 5 \mathrm{H}_{2} \mathrm{O}$ & $35.21 \mathrm{mg}$ & $0.14 \mathrm{mM}$ \\
\hline $\mathrm{Na}_{2} \mathrm{MoO}_{4} \cdot 2 \mathrm{H}_{2} \mathrm{O}$ & $46 \mathrm{mg}$ & $0.19 \mathrm{mM}$ \\
\hline $\mathrm{NiCl}_{2} \cdot 6 \mathrm{H}_{2} \mathrm{O}$ & $90 \mathrm{mg}$ & $0.38 \mathrm{mM}$ \\
\hline $\mathrm{VCl}_{3}$ & $30 \mathrm{mg}$ & $0.19 \mathrm{mM}$ \\
\hline
\end{tabular}

\subsection{Membrane Experiment, Binding Assay}

To investigate the interaction behavior of Amt-GlnK, membrane fractions were isolated natively. Approximately $7 \mathrm{~g}$ of $M$. thermolithotrophicus cells were lysed by the addition of $50 \mathrm{~mL}$ lysis buffer (50 mM Tricine/ $\mathrm{NaOH} \mathrm{pH} 8$ and $2 \mathrm{mM}$ dithiothreitol, DTT) followed by sonication (five cycles of $10 \mathrm{~s}$ sonication at $\sim 65 \%$ intensity with $20 \mathrm{~s}$ breaks, probe MS73, Bandelin SONOPULS, Berlin, Germany, ) and centrifuged at $45,000 \times g$ for $45 \mathrm{~min}$ at $20^{\circ} \mathrm{C}$. The cell lysate was transferred and centrifuged at $150,000 \times g$ for $1 \mathrm{~h}$ at $25^{\circ} \mathrm{C}$ in an ultracentrifuge (Beckman Coulter Life Sciences, Krefeld, Germany, L-70) to isolate the membrane fraction. The supernatant was discarded, and the membrane fraction was resuspended in the washing buffer $(50 \mathrm{mM}$ Tris/ $\mathrm{HCl} \mathrm{pH} \mathrm{7.6,500} \mathrm{mM} \mathrm{NaCl}$ and $2 \mathrm{mM}$ DTT) followed by ultracentrifugation at $150,000 \times \mathrm{g}$ for $1 \mathrm{~h}$ at $25^{\circ} \mathrm{C}$. This washing procedure was performed four times. The pellet was resuspended in the lysis buffer and split evenly in 10 aliquots of $10 \mathrm{~mL}$. The following metabolites were then added: (1) no effector; (2) $2 \mathrm{mM} \mathrm{MgCl}$, $2 \mathrm{mM} \mathrm{ADP}$; (3) $2 \mathrm{mM} \mathrm{MgCl} 2,2 \mathrm{mM}$ ATP; (4) $2 \mathrm{mM} \mathrm{MgCl}, 10 \mathrm{mM} 2 \mathrm{OG}$ (oxoglutarate sodium salt); (5) $2 \mathrm{mM} \mathrm{MgCl} 2,2 \mathrm{mM}$ ATP, $10 \mathrm{mM}$ 2OG; (6) $2 \mathrm{mM} \mathrm{MgCl}$, $2 \mathrm{mM}$ ADP, $10 \mathrm{mM}$ 2OG; (7) $2 \mathrm{mM} \mathrm{MgCl}$, 2 mM ADP, 2 mM ATP, $10 \mathrm{mM}$ 2OG; (8) $2 \mathrm{mM}$ $\mathrm{MgCl}_{2}$, 2mM ADP, $20 \mathrm{mM}$ ATP, 10 mM 2OG; (9) $2 \mathrm{mM}$ ATP, $10 \mathrm{mM}$ 2OG; (10) $2 \mathrm{mM} \mathrm{MgCl}$, $2 \mathrm{mM}$ GTP, $10 \mathrm{mM}$ 2OG. All conditions were incubated for $30 \mathrm{~min}$ at room temperature, then centrifuged at $150,000 \times g$ for $1 \mathrm{~h}$ at $25{ }^{\circ} \mathrm{C}$. The supernatant was concentrated to $100 \mu \mathrm{L}$ in a $10-\mathrm{kDa}$ cut-off concentrator (Vivaspin ${ }^{\circledR} 20$, Sartorius, Göttingen, Germany) and analyzed by SDS-PAGE (Anode buffer: $100 \mathrm{mM}$ Tris base and $22.5 \mathrm{mM} \mathrm{HCl}, \mathrm{pH} 8.9$ and Cathode buffer: $100 \mathrm{mM}$ Tris base, $100 \mathrm{mM}$ Tricine and $0.1 \%$ sodium dodecyl sulfate (SDS) $\mathrm{pH} 8.25$ ) for $90 \mathrm{~min}$ at 90 Volts. The gel was stained with InstantBlue ${ }^{\mathrm{TM}}$ (Expedeon, Cambridgeshire, UK).

\subsection{Protein Identification by Mass Spectrometry}

Selected Coomassie stained bands were excised, and the proteins within were reduced by DTT, alkylated by iodoacetamide and digested overnight with trypsin. The resulting peptides were extracted twice by $5 \%$ formic acid and the extracts were pooled together and dried down. The samples were then reconstituted in $25 \mu \mathrm{L}$ of $5 \%$ formic acid containing $5 \mathrm{fmol} / \mu \mathrm{L}$ retention time standard peptides (Pierce, Rockford, IL, USA) and $5 \mu \mathrm{L}$ were taken for LC-MS/MS analysis.

LC-MS/MS analysis was performed by MS Facility at the MPI-CBG Dresden, Germany, on a nano-UPLC Ultimate 3000 interfaced on-line to an Orbitrap HF hybrid mass spectrometer (both Thermo Fischer Scientific, Bremen, Germany). The UPLC system was equipped with Acclaim ${ }^{\mathrm{TM}}$ PepMap ${ }^{\mathrm{TM}}$ 100, $75 \mu \mathrm{m} \times 2 \mathrm{~cm}$ trapping column (Thermo Fischer Scientific, Bremen, Germany) and $50 \mathrm{~cm} \mu \mathrm{Pac}$ micro Pillar Array separating column (PharmaFluidics, Ghent, Belgium). Peptides were separated using 75 min linear gradients $0 \%$ to $65 \%$ of acetonitrile (solvent $\mathrm{A}-0.1 \%$ formic acid in water, solvent $\mathrm{B}-0.1 \%$ formic acid in 
neat acetonitrile). Spectra were acquired using Top20 data-dependent acquisition method, precursor $m / z$ range was 350-1600 and dynamic exclusion time was $15 \mathrm{~s}$. The lock-mass function was set to recalibrate MS1 scans using the background ion $\left(\mathrm{Si}\left(\mathrm{CH}_{3}\right)_{2} \mathrm{O}\right)_{6}$ at $\mathrm{m} / \mathrm{z}$ 445.12. Acquired spectra were searched by MASCOT software (version 2.2.04) against $M$. thermolithotrophicus protein sequences in NCBI database (1799 entries, September 2020) and genome (6-frames translation). Mass tolerance was set to $5 \mathrm{ppm}$ and $0.025 \mathrm{Da}$ for precursor and fragment ions respectively; two miscleavages; variable modifications-cysteine carbamidomethyl, propionamide; methionine oxidized. The results were evaluated by Scaffold software (Proteome Software version 4.11.0, Portland, USA), minimum number of matched peptides was set to two; peptide and protein false discovery rate (FDR) was below $1 \%$.

The total spectrum counts for $M t G \operatorname{lnK} K_{1}$ and $M t G \operatorname{lnK} K_{2}$ were 346 and 784, respectively for the Mg-ATP/2OG condition (from the gel of Figure 1); 420 and 869 for the Mg-ATPADP/2OG condition; 244 and 705 for the ATP/2OG condition.

\subsection{GlnKs Expression and Purification}

$M t G \operatorname{lnK} K_{1}, M t G \operatorname{lnK} K_{2}$ sequences originate from $M$. thermolithotrophicus strain DSM 2095 and $M j G \operatorname{lnK} K_{1}$ sequence originates from $M$. jannaschii strain DSM 2661. DNA coding sequences were codon optimized (refer to the supplementary data for the sequences) and synthesized by Genscript (Leiden, Netherlands). For $M t G \ln K_{1}$ and $M t G \ln K_{2}$, NdeI/BamHI restriction sites were added in the $5^{\prime}$ - and $3^{\prime}$-extremities, respectively. Both synthetic genes were cloned in a pET-28a(+) vector by Genscript.

For $M j G \operatorname{lnK} K_{1}$, NdeI and XhoI restriction sites were added in the $5^{\prime}$ - and $3^{\prime}$-extremities, respectively. A stop codon was also added upstream of the XhoI site in $3^{\prime}$. The DNA synthesized was cloned in the expression vector $\mathrm{pET}-24 \mathrm{~b}(+)$ at the NdeI and XhoI restriction enzyme digestion sites by Genscript.

Each construct was expressed in Escherichia coli strain BL21(DE3) cultivated in Lysogeny Broth supplemented with a final concentration of $50 \mu \mathrm{g} / \mathrm{mL}$ kanamycin. The cultures were incubated at $37^{\circ} \mathrm{C}$, being shaken, until an $\mathrm{OD}_{600}$ of $0.6-0.8$ was reached. Induction was performed by adding Isopropyl B-D-1-thiogalactopyranoside at a final concentration of $0.75 \mathrm{mM}$ and the cells were incubated for another hour at $37^{\circ} \mathrm{C}$, being shaken. The cells were harvested by centrifugation at $5000 \times \mathrm{g}$ for $20 \mathrm{~min}$ at $21^{\circ} \mathrm{C}$. Subsequently, the cell pellet was washed in phosphate buffered saline solution and centrifuged for $20 \mathrm{~min}$ at $4000 \times g$ at room temperature. The washed cell pellets were flash-frozen in liquid nitrogen.

The frozen cell pellets were thawed and resuspended in the lysis buffer $(50 \mathrm{mM}$ Tricine/ $\mathrm{NaOH}$ pH 8, $2 \mathrm{mM}$ DTT) at a ratio of $4 \mathrm{~mL}$ lysis buffer per gram of wet weight. The cells were disrupted by sonication (10 cycles of $20 \mathrm{~s}$ at $70 \%$ intensity with $30 \mathrm{~s}$ breaks, probe KE 76, Bandelin SONOPULS, Berlin, Germany) on ice. The lysate was centrifuged at $45,000 \times g$ at room temperature for $40 \mathrm{~min}$. The supernatant was then heated up to $70{ }^{\circ} \mathrm{C}$ for $30 \mathrm{~min}$ followed by centrifugation for $20 \mathrm{~min}$ at $45,000 \times \mathrm{g}$. The supernatant was filtered through $0.2 \mu \mathrm{m}$ (Sartorius, Göttingen, Germany) and placed at $4{ }^{\circ} \mathrm{C}$ overnight, standing.

For $M t G \ln K_{1}$ and $M t G \ln K_{2}$, a white precipitate appeared overnight and the sample was centrifuged at $45,000 \times g$ for $30 \mathrm{~min}$ at $4{ }^{\circ} \mathrm{C}$. The pellets, corresponding to the protein of interest, were resuspended in $4 \mathrm{~mL}$ of gel filtration buffer $(25 \mathrm{mM}$ Tris $/ \mathrm{HCl} \mathrm{pH} \mathrm{7.6,}$ $10 \%$ glycerol, $2 \mathrm{mM}$ DTT, $500 \mathrm{mM} \mathrm{NaCl}$ ) and the aggregates were dissolved by heating at $70{ }^{\circ} \mathrm{C}$ for $15 \mathrm{~min}$ followed by centrifugation $13,000 \times \mathrm{g}$ for $5 \mathrm{~min}$ RT. The supernatants were immediately injected on a HiLoad ${ }^{\circledR} 16 / 600$ Superdex ${ }^{\circledR} 200$ pg (GE Healthcare, Freiburg, Germany). The protein was eluted at a flow rate of $1 \mathrm{~mL} / \mathrm{min}$ at room temperature. $M t G \ln K_{1}$ eluted as a single gaussian peak at $82 \mathrm{~mL}$, from which the fractions of interest were pooled. $M t G \operatorname{lnK} K_{2}$ major peak eluted at $86.6 \mathrm{~mL}$. Both pools were concentrated with a 10-kDa cut-off concentrator (Vivaspin ${ }^{\circledR} 20$, Sartorius, Göttingen, Germany) at room temperature and centrifuged at $13,000 \times g$ for $5 \mathrm{~min}$ to remove aggregates.

For $M j \mathrm{GlnK}_{1}$, no precipitate appeared after the overnight incubation at $4{ }^{\circ} \mathrm{C}$. The sample was filtered through $0.2 \mu \mathrm{m}$ (Sartorius, Göttingen, Germany) and immediately injected 
on a HiLoad 16/600 Superdex 200pg (GE Healthcare, Freiburg, Germany). The sample eluted at a flow rate of $1 \mathrm{~mL} / \mathrm{min}$ in the gel filtration buffer and four peaks were observable at elution volumes of $62,66,73$ and $80 \mathrm{~mL}$. The four different pools were concentrated with a 10-kDa cut-off concentrator (Vivaspin ${ }^{\circledR} 20$, Sartorius, Göttingen, Germany) at room temperature and centrifuged at $13,000 \times g$ for 5 min to remove aggregates.

All purification steps were systematically checked by SDS-PAGE. The protein concentration was determined via Bradford assay. All GlnKs passed on SDS-PAGE exhibited an extra band at $25-\mathrm{kDa}$, in addition to the expected monomeric molecular weight (circa $12 \mathrm{kDa})$, as observed in other GlnK studies [31].

\subsection{Crystallization}

All purified proteins were immediately crystallized at $18{ }^{\circ} \mathrm{C}$. Initial screening was performed by using the sitting drop method on 96-Well MRC 2-Drop Crystallization Plates in polystyrene (SWISSCI, Neuheim, Switzerland) containing $90 \mu \mathrm{L}$ of crystallization solution in the reservoir. $0.6 \mu \mathrm{L}$ sample with $0.6 \mu \mathrm{L}$ crystallization solution were spotted. For all three GlnKs, the protein sample was crystallized with and without $2 \mathrm{mM}$ ATP, $2 \mathrm{mM}$ $2 \mathrm{OG}$ and $2 \mathrm{mM} \mathrm{MgCl}_{2}$. Since $M t G \ln K_{1}$ and $M t G \ln K_{2}$ with ligands aggregated strongly at $18{ }^{\circ} \mathrm{C}$, the protein sample was first heated to $70{ }^{\circ} \mathrm{C}$ and centrifuged at $13,000 \times g$ for $5 \mathrm{~min}$ at room temperature to remove remaining aggregates before spotting.

$M t G \ln K_{1}$ at a concentration of $33 \mathrm{mg} / \mathrm{mL}$ co-crystallized with ligands generated few crystals but none of them diffracted to an exploitable resolution. However, hexagonal rods instantly appeared for $M t \mathrm{GlnK}_{1}$ at $33 \mathrm{mg} / \mathrm{mL}$ without ligands in 35\% $w / v$ Pentaerythritol propoxylate (17/8 PO/OH), $100 \mathrm{mM}$ MES; pH 6.5 and $200 \mathrm{mM}$ ammonium sulfate.

$M t \mathrm{GlnK}_{2}$ at a concentration of $30 \mathrm{mg} / \mathrm{mL}$ without ligand crystallized as small squares in 35\% $w / v$ Pentaerythritol ethoxylate (15/4 EO/OH) and $100 \mathrm{mM} \mathrm{HEPES} \mathrm{pH} \mathrm{7.5.} \mathrm{When}$ $M t \mathrm{GlnK}_{2}$ at $30 \mathrm{mg} / \mathrm{mL}$ was crystallized with ligands, high-quality shard shaped crystals appeared after minutes in 25\% w/v Pentaerythritol ethoxylate $(3 / 4 \mathrm{EO} / \mathrm{OH})$ and $100 \mathrm{mM}$ MES pH 6.5.

As stated above, four pools of purified $M j \mathrm{GlnK}_{1}$ were obtained after gel filtration. The best crystals were obtained from the pool containing the protein eluted at $66 \mathrm{~mL}$ on the gel filtration. This pool, concentrated to $11.2 \mathrm{mg} / \mathrm{mL}$, was co-crystallized with ligands and high-quality cube-shaped crystals appeared overnight in 20\% w/v PEG 3350, $100 \mathrm{mM}$ Bis-Tris propane $\mathrm{pH} 8.5$ and $200 \mathrm{mM}$ sodium nitrate.

\subsection{X-Ray Crystallography Data Collection, Refinement and Analyses}

$M j \mathrm{GlnK}_{1}$ crystals were soaked in their crystallization solutions supplemented with $20 \% v / v$ glycerol as a cryo-protectant prior to being frozen in liquid nitrogen. $M t G \ln K_{2}$ crystals with ligands were soaked in the crystallization solution supplemented with $60 \mathrm{mM}$ Tb-Xo4 (Molecular Dimensions, Sheffield, UK) for $3 \mathrm{~min} 30 \mathrm{~s}$ prior to being frozen in liquid nitrogen. The Tb-Xo4 had no effect on the diffraction quality and was not detected in the electron density.

X-ray diffraction was collected at $100 \mathrm{~K}$ at the Synchrotron Source optimisée de lumière d'énergie intermédiaire du LURE (SOLEIL), PROXIMA-1 beamline; the Swiss Light Source (SLS), X06DA and X10SA beamlines and at PETRA-III, P11 beamline. The best datasets were obtained at the Swiss Light Source (SLS), X06DA and X10SA beamlines.

Data were processed and scaled with autoPROC (Version 1.0.5, Global Phasing Limited, Cambridge, UK) [32]. The structures were solved by molecular replacement with phaser from the PHENIX package (Version 1.19.2-4158) [33], using $M_{j} \mathrm{GlnK}_{1}$ (PDB 2J9D) as a template. All models were then manually rebuilt with COOT (Version 0.8.9.2) [34] and further refined with PHENIX. MtGlnK 2 and $M j G \ln K_{1}$ with ligands were refined by considering all atoms anisotropic. $M t G \ln K_{2}$ apo was refined with applied translational-liberation screw and twinning refinement, considering a twin fraction of 0.39 with the following twin law: h, k, -l. MtGlnK $\mathrm{K}_{1}-\mathrm{dADP}$ was also refined by applying translational-liberation screw. For all 
models, hydrogens were added in riding position for the last refinement cycles except for $M t G \ln K_{2}$ apo. Hydrogens were omitted for the final deposited model.

All models were validated through the MolProbity server (http:/ / molprobity.biochem. duke.edu, accessed on 8 July 2021) [35]. Data collection and refinement statistics, as well as PDB identification codes for the deposited models and structure factors are listed in Table 3.

Table 3. X-ray crystallographic data and refinement statistics.

\begin{tabular}{|c|c|c|c|c|}
\hline & $M t G \ln K_{1}$ with dADP & $M t \mathrm{GlnK}_{2}$ apo & $\begin{array}{c}M t G \ln K_{2} \text { with ATP, Mg } \\
\text { and 2OG }\end{array}$ & $\begin{array}{c}M j \mathrm{GlnK} \mathrm{K}_{1} \text { with ATP, } \mathrm{Mg} \\
\text { and 2OG }\end{array}$ \\
\hline \multicolumn{5}{|l|}{ Data collection } \\
\hline Synchrotron source & SLS, PXIII & SLS, PXIII & SLS, PXIII & SLS, PXIII \\
\hline Wavelength $(\AA)$ & 1.00003 & 0.99187 & 0.99985 & 0.99187 \\
\hline Space group & P321 & $P 2{ }_{1} 2{ }_{1} 2$ & $P 4_{3} 2{ }_{1} 2$ & H32 \\
\hline & $75.60-1.94$ & $73.16-2.30$ & $57.33-1.16$ & $44.53-1.20$ \\
\hline Resolution (A) & $(2.15-1.94)$ & $(2.40-2.30)$ & $(1.26-1.16)$ & $(1.24-1.20)$ \\
\hline \multicolumn{5}{|l|}{ Cell dimensions } \\
\hline a, b, c $(\AA)$ & $87.296,87.296,46.010$ & $103.461,103.460,178.491$ & $58.238,58.238,229.304$ & $89.053,89.053,98.059$ \\
\hline$\alpha, \beta, \gamma\left({ }^{\circ}\right)$ & $90,90,120$ & $90,90,90$ & $90,90,90$ & $90,90,120$ \\
\hline $\mathrm{R}_{\text {merge }}(\%)^{\text {a }}$ & $5.3(171.1)$ & $13.3(115.1)$ & $4.9(64.3)$ & $5.7(120.9)$ \\
\hline$R_{\text {pim }}(\%)^{a}$ & $1.3(40.3)$ & $5.5(50.8)$ & $1.0(28.6)$ & $2.0(44.3)$ \\
\hline $\mathrm{CC}_{1 / 2}{ }^{\mathrm{a}}$ & $0.999(0.773)$ & $0.998(0.671)$ & $0.999(0.774)$ & $0.999(0.642)$ \\
\hline $\mathrm{I} / \sigma_{I} \mathrm{a}^{\mathrm{a}}$ & $27.3(1.8)$ & $10.2(1.5)$ & $29.1(1.7)$ & $17.8(1.7)$ \\
\hline Spherical completeness ${ }^{a}$ & $66.3(12.7)$ & $82.1(35)$ & $78.1(17.7)$ & $67.8(34.6)$ \\
\hline Ellipsoidal completeness ${ }^{a}$ & $89.1(60.2)$ & $96.2(81.3)$ & $93.2(51.7)$ & $89.8(99.6)$ \\
\hline Redundancy ${ }^{a}$ & $19.3(18.6)$ & $6.7(6.0)$ & $21.6(5.2)$ & $9.4(8.3)$ \\
\hline Nr. unique reflections ${ }^{a}$ & $10,108(502)$ & $70,360(3519)$ & $108,153(5406)$ & $31,673(1585)$ \\
\hline \multicolumn{5}{|l|}{ Refinement } \\
\hline Resolution $(\AA)$ & $39.30-1.94$ & $73.16-2.30$ & $57.33-1.16$ & $44.53-1.20$ \\
\hline Number of reflections & 9995 & 70,326 & 108,153 & 31,668 \\
\hline $\mathrm{R}_{\text {work }} / \mathrm{R}_{\text {free }}{ }^{\mathrm{b}}(\%)$ & $19.66 / 22.57$ & $22.15 / 24.45$ & $11.68 / 13.66$ & $13.11 / 15.54$ \\
\hline \multicolumn{5}{|l|}{ Number of atoms } \\
\hline Protein & 882 & 9066 & 2788 & 953 \\
\hline Ligands/ions & 28 & 13 & 145 & 52 \\
\hline Solvent & 23 & 104 & 516 & 178 \\
\hline Mean B-value $\left(\AA^{2}\right)$ & 62.0 & 37.0 & 20.0 & 21.0 \\
\hline Molprobity clash score, all atoms & 1.63 & 3.89 & 0.67 & 0 \\
\hline \multicolumn{5}{|l|}{ Ramachandran plot } \\
\hline Favored regions (\%) & 100 & 98.75 & 100 & 100 \\
\hline Outlier regions $(\%)$ & 0 & 0 & 0 & 0 \\
\hline rmsd ${ }^{c}$ bond lengths $(\AA)$ & 0.013 & 0.006 & 0.014 & 0.012 \\
\hline rmsd ${ }^{\mathrm{C}}$ bond angles $\left({ }^{\circ}\right)$ & 1.454 & 0.888 & 1.592 & 1.565 \\
\hline PDB ID code & $7 \mathrm{P} 4 \mathrm{~V}$ & $7 \mathrm{P} 4 \mathrm{Y}$ & $7 \mathrm{P} 50$ & 7P52 \\
\hline
\end{tabular}

${ }^{a}$ Values relative to the highest resolution shell are within parentheses. ${ }^{b} R_{\text {free }}$ was calculated as the $R_{\text {work }}$ for $5 \%$ of the reflections that were not included in the refinement. ${ }^{c}$ rmsd, root mean square deviation.

\subsection{Structural Analyses}

Sequence alignment was performed with Clustal Omega (https:/ / www.ebi.ac.uk/ Tools/msa/clustalo/, accessed on 6 July 2021) [36] and analysis was performed with Espript (Version 3.0) [37]. The homology modelling of $A m t B_{1}$ and $A m t B_{2}$ from Methanothermococcus thermolithotrophicus based on E. coli structure (PDB 2NUU) was performed by the Phyre2 server (http:/ / www.sbg.bio.ic.ac.uk/phyre2/html/page.cgi?id=index, accessed on 6 July 2021) [38]. All figures of protein structure were generated with PyMOL (Version Open-Source PyMOL ${ }^{\mathrm{TM}}$ 1.8.x) (Schrödinger, LLC). Sequence conservation score superposed to the $M t \mathrm{GlnK}_{2}-\mathrm{Mg}$-ATP/2OG structure was performed with the ConSurf server (https:/ / consurf.tau.ac.il/credits.php, accessed on 6 July 2021) [25,26].

\section{Conclusions}

Our work emphasized the structural conservation among GlnKs and the importance of the free carboxy group at the C-terminal to optimize ligand coordination. Therefore, adding a tag at this position should be avoided in future studies on the close members of this protein family to avoid unwanted artefacts.

While our results show that GlnKs from Methanococcales do not structurally and mechanistically differ from previously characterized GlnKs, another group of $\mathrm{P}_{\text {II }}$ proteins present in diazotrophic methanogens might have different properties. These two genes coding for $\mathrm{Nifl}_{1}$ and $\mathrm{Nifl}_{2}$ are always co-located within the nitrogenase operon and regulate $\mathrm{N}_{2}$-fixation [7]. They are phylogenetically different from GlnKs and biochemical charac- 
terization suggested unique traits regarding their oligomerization. Future studies will be necessary to reveal whether NifI is a structural exception within the very well conserved $\mathrm{P}_{\mathrm{II}}$-family.

Supplementary Materials: The following are available online at https:/ / www.mdpi.com/article/10 $.3390 /$ ijms22168631/s1.

Author Contributions: M.-C.M. and T.W. contributed to the study design, data collection, processing, analyses as well as the data validation. The manuscript was written and corrected by M.-C.M. and T.W. Both authors have read and agreed to the published version of the manuscript.

Funding: The research was funded by the Max-Planck Gesellschaft.

Institutional Review Board Statement: Not applicable.

Informed Consent Statement: Not applicable.

Data Availability Statement: The structures were deposited in the protein data bank under the following ID codes: $7 \mathrm{P} 4 \mathrm{~V}$ for $M t \mathrm{GlnK}_{1}-\mathrm{dADP}, 7 \mathrm{P} 4 \mathrm{Y}$ for $M t \mathrm{GlnK}_{2}$ apo form, 7P50 for $M t \mathrm{GlnK}_{2}-\mathrm{Mg}$ ATP/2OG and 7P52 for $M j \mathrm{GlnK}_{1}-\mathrm{Mg}-\mathrm{ATP} / 2 \mathrm{OG}$.

Acknowledgments: We thank the Max Planck Institute for Marine Microbiology and the Max-PlanckSociety for continuous support. We thank the MS Facility at MPI CBG, Dresden, for MS-analysis of the protein and especially Anna Shevchenko for her help. We acknowledge the SOLEIL synchrotron, SLS synchrotron and PETRA-III synchrotron for beamtime allocation and the beamline staff for assistance with data collection with a special acknowledgement to Sylvain Engilberge. We are also thankful to Christina Probian and Ramona Appel for their continuous support in the Microbial Metabolism laboratory. We further thank Nevena Maslać for performing the fermenter cultivation steps and Grace Ho for proof reading.

Conflicts of Interest: The authors declare no conflict of interest.

\section{References}

1. Huergo, L.F.; Chandra, G.; Merrick, M. $\mathrm{P}_{\mathrm{II}}$ signal transduction proteins: Nitrogen regulation and beyond. FEMS Microbiol. Rev. 2013, 37, 251-283. [CrossRef]

2. Conroy, M.J.; Durand, A.; Lupo, D.; Li, X.D.; Bullough, P.A.; Winkler, F.K.; Merrick, M. The crystal structure of the Escherichia coli AmtB-GlnK complex reveals how GlnK regulates the ammonia channel. Proc. Natl. Acad. Sci. USA 2007, 104, 1213-1218. [CrossRef]

3. Gruswitz, F.; O'Connell, J., 3rd; Stroud, R.M. Inhibitory complex of the transmembrane ammonia channel, AmtB, and the cytosolic regulatory protein, GlnK, at $1.96 \AA$ A. Proc. Natl. Acad. Sci. USA 2007, 104, 42-47. [CrossRef]

4. Shapiro, B.M. The Glutamine Synthetase Deadenylylating Enzyme System from Escherichia coli. Resolution into Two Components, Specific Nucleotide Stimulation, and Cofactor Requirements. Biochemistry 1969, 8, 659-670. [CrossRef]

5. $\quad$ Ehlers, C.; Weidenbach, K.; Veit, K.; Forchhammer, K.; Schmitz, R.A. Unique mechanistic features of post-translational regulation of glutamine synthetase activity in Methanosarcina mazei strain Gö1 in response to nitrogen availability. Mol. Microbiol. 2005, 55, 1841-1854. [CrossRef]

6. Kessler, P.S.; Daniel, C.; Leigh, J.A. Ammonia Switch-Off of Nitrogen Fixation in the Methanogenic Archaeon Methanococcus maripaludis: Mechanistic Features and Requirement for the Novel GlnB Homologues, $\mathrm{NifI}_{1}$ and NifI 2 . J. Bacteriol. 2001, 183, 882-889. [CrossRef]

7. Leigh, J.A.; Dodsworth, J.A. Nitrogen Regulation in Bacteria and Archaea. Annu. Rev. Microbiol. 2007, 61, 349-377. [CrossRef]

8. Little, R.; Colombo, V.; Leech, A.; Dixon, R. Direct Interaction of the NifL Regulatory Protein with the GlnK Signal Transducer Enables the Azotobacter vinelandii NifL-NifA Regulatory System to Respond to Conditions Replete for Nitrogen. J. Biol. Chem. 2002, 277, 15472-15481. [CrossRef]

9. He, L.; Soupene, E.; Ninfa, A.; Kustu, S. Physiological role for the GlnK protein of enteric bacteria: Relief of NifL inhibition under nitrogen-limiting conditions. J. Bacteriol. 1998, 180, 6661-6667. [CrossRef]

10. Scholl, J.; Dengler, L.; Bader, L.; Forchhammer, K. Phosphoenolpyruvate carboxylase from the cyanobacterium Synechocystis sp. PCC 6803 is under global metabolic control by $\mathrm{P}_{\mathrm{II}}$ signaling. Mol. Microbiol. 2020, 114, 292-307. [CrossRef]

11. Selim, K.A.; Haase, F.; Hartmann, M.D.; Hagemann, M.; Forchhammer, K. PII-like signaling protein SbtB links cAMP sensing with cyanobacterial inorganic carbon response. Proc. Natl. Acad. Sci. USA 2018, 115, E4861-E4869. [CrossRef] [PubMed]

12. Ninfa, A.J.; Jiang, P. PII signal transduction proteins: Sensors of $\alpha$-ketoglutarate that regulate nitrogen metabolism. Curr. Opin. Microbiol. 2005, 8, 168-173. [CrossRef]

13. Jiang, P.; Ninfa, A.J. Escherichia coli PII Signal Transduction Protein Controlling Nitrogen Assimilation Acts As a Sensor of Adenylate Energy Charge in Vitro. Biochemistry 2007, 46, 12979-12996. [CrossRef] 
14. Forchhammer, K.; Luddecke, J. Sensory properties of the $\mathrm{P}_{\mathrm{II}}$ signalling protein family. FEBS J. 2016, 283, 425-437. [CrossRef]

15. Sant'Anna, F.H.; Trentini, D.B.; de Souto Weber, S.; Cecagno, R.; da Silva, S.C.; Schrank, I.S. The PII Superfamily Revised: A Novel Group and Evolutionary Insights. J. Mol. Evol. 2009, 68, 322-336. [CrossRef] [PubMed]

16. Brown, M.S.; Segal, A.; Stadtman, E.R. Modulation of Glutamine Synthetase Adenylylation and Deadenylylation Is Mediated by Metabolic Transformation of the $\mathrm{P}_{\mathrm{II}}$-Regulatory Protein. Proc. Natl. Acad. Sci. USA 1971, 68, 2949-2953. [CrossRef] [PubMed]

17. Maier, S.; Schleberger, P.; Lu, W.; Wacker, T.; Pfluger, T.; Litz, C.; Andrade, S.L. Mechanism of Disruption of the Amt-GlnK Complex by $\mathrm{P}_{\mathrm{II}}$-Mediated Sensing of 2-Oxoglutarate. PLoS ONE 2011, 6, e26327. [CrossRef] [PubMed]

18. Pedro-Roig, L.; Lange, C.; Bonete, M.J.; Soppa, J.; Maupin-Furlow, J. Nitrogen regulation of protein-protein interactions and transcript levels of GlnK PII regulator and AmtB ammonium transporter homologs in Archaea. Microbiologyopen 2013, 2, 826-840. [CrossRef] [PubMed]

19. Yildiz, Ö.; Kalthoff, C.; Raunser, S.; Kuhlbrandt, W. Structure of GlnK1 with bound effectors indicates regulatory mechanism for ammonia uptake. EMBO J. 2007, 26, 589-599. [CrossRef]

20. Leigh, J.A. Nitrogen Fixation In Methanogens: The Archaeal Perspective. Curr. Issues Mol. Biol. 2000, 2, 125-131. [CrossRef] [PubMed]

21. Radchenko, M.V.; Thornton, J.; Merrick, M. Control of AmtB-GlnK Complex Formation by Intracellular Levels of ATP, ADP, and 2-Oxoglutarate. J. Biol. Chem. 2010, 285, 31037-31045. [CrossRef]

22. Truan, D.; Huergo, L.F.; Chubatsu, L.S.; Merrick, M.; Li, X.D.; Winkler, F.K. A New PII Protein Structure Identifies the 2Oxoglutarate Binding Site. J. Mol. Biol. 2010, 400, 531-539. [CrossRef]

23. Moure, V.R.; Razzera, G.; Araújo, L.M.; Oliveira, M.A.S.; Gerhardt, E.C.M.; Müller-Santos, M.; Almeida, F.; Pedrosa, F.O.; Valente, A.P.; Souza, E.M.; et al. Heat stability of Proteobacterial $\mathrm{P}_{\text {II }}$ protein facilitate purification using a single chromatography step. Protein Expr. Purif. 2012, 81, 83-88. [CrossRef]

24. Cheah, E.; Carr, P.D.; Suffolk, P.M.; Vasudevan, S.G.; Dixon, N.E.; Ollis, D.L. Structure of the Escherichia coli signal transducing protein $\mathrm{P}_{\mathrm{II}}$. Structure 1994, 2, 981-990. [CrossRef]

25. Landau, M.; Mayrose, I.; Rosenberg, Y.; Glaser, F.; Martz, E.; Pupko, T.; Ben-Tal, N. ConSurf 2005: The projection of evolutionary conservation scores of residues on protein structures. Nucleic Acids Res. 2005, 33, W299-W302. [CrossRef]

26. Glaser, F.; Pupko, T.; Paz, I.; Bell, R.E.; Bechor-Shental, D.; Martz, E.; Ben-Tal, N. ConSurf: Identification of Functional Regions in Proteins by Surface-Mapping of Phylogenetic Information. Bioinformatics 2003, 19, 163-164. [CrossRef]

27. Arcondéguy, T.; Jack, R.; Merrick, M. P II Signal Transduction Proteins, Pivotal Players in Microbial Nitrogen Control. Microbiol. Mol. Biol. Rev. 2001, 65, 80-105. [CrossRef]

28. Helfmann, S.; Lü, W.; Litz, C.; Andrade, S.L. Cooperative Binding of MgATP and MgADP in the Trimeric P Protein GlnK2 from Archaeoglobus fulgidus. J. Mol. Biol. 2010, 402, 165-177. [CrossRef]

29. Chellamuthu, V.R.; Ermilova, E.; Lapina, T.; Luddecke, J.; Minaeva, E.; Herrmann, C.; Hartmann, M.D.; Forchhammer, K. A Widespread Glutamine-Sensing Mechanism in the Plant Kingdom. Cell 2014, 159, 1188-1199. [CrossRef] [PubMed]

30. Wacker, T.; Garcia-Celma, J.J.; Lewe, P.; Andrade, S.L. Direct observation of electrogenic $\mathrm{NH}_{4}^{+}$transport in ammonium transport (Amt) proteins. Proc. Natl. Acad. Sci. USA 2014, 111, 9995-10000. [CrossRef]

31. Pedro-Roig, L.; Camacho, M.; Bonete, M.J. Regulation of ammonium assimilation in Haloferax mediterranei: Interaction between glutamine synthetase and two GlnK proteins. Biochim. Biophys. Acta 2013, 1834, 16-23. [CrossRef] [PubMed]

32. Vonrhein, C.; Flensburg, C.; Keller, P.; Sharff, A.; Smart, O.; Paciorek, W.; Womack, T.; Bricogne, G. Data processing and analysis with the autoPROC toolbox. Acta Crystallogr. D Biol. Crystallogr. 2011, 67, 293-302. [CrossRef]

33. Afonine, P.V.; Grosse-Kunstleve, R.W.; Echols, N.; Headd, J.J.; Moriarty, N.W.; Mustyakimov, M.; Terwilliger, T.C.; Urzhumtsev, A.; Zwart, P.H.; Adams, P.D. Towards automated crystallographic structure refinement with phenix.refine. Acta Crystallogr. D Biol. Crystallogr. 2012, 68, 352-367. [CrossRef]

34. Emsley, P.; Lohkamp, B.; Scott, W.G.; Cowtan, K. Features and development of Coot. Acta Crystallogr. D Biol. Crystallogr. 2010, 66, 486-501. [CrossRef] [PubMed]

35. Williams, C.J.; Headd, J.J.; Moriarty, N.W.; Prisant, M.G.; Videau, L.L.; Deis, L.N.; Verma, V.; Keedy, D.A.; Hintze, B.J.; Chen, V.B.; et al. MolProbity: More and better reference data for improved all-atom structure validation. Protein Sci. 2018, 27, 293-315. [CrossRef] [PubMed]

36. Madeira, F.; Park, Y.M.; Lee, J.; Buso, N.; Gur, T.; Madhusoodanan, N.; Basutkar, P.; Tivey, A.R.N.; Potter, S.C.; Finn, R.D.; et al. The EMBL-EBI search and sequence analysis tools APIs in 2019. Nucleic Acids Res. 2019, 47, W636-W641. [CrossRef] [PubMed]

37. Robert, X.; Gouet, P. Deciphering key features in protein structures with the new ENDscript server. Nucleic Acids Res. 2014, 42, W320-W324. [CrossRef] [PubMed]

38. Kelley, L.A.; Mezulis, S.; Yates, C.M.; Wass, M.N.; Sternberg, M.J. The Phyre2 web portal for protein modeling, prediction and analysis. Nat. Protoc. 2015, 10, 845-858. [CrossRef] 